Aletria, Belo Horizonte, v. 31, n. 3, p. 187-208, 2021

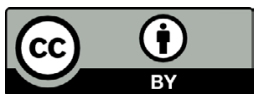

\title{
Violência e escapismo como lazer para os desvalidos em Trainspotting e Cola de Irvine Welsh
}

\section{Violence and Escapism as Leisure for the Underprivileged in Irvine Welsh's Trainspotting and Glue}

\author{
Amaury Garcia dos Santos Neto \\ Universidade do Estado do Rio de Janeiro (UERJ), Rio de Janeiro, Rio de Janeiro / Brasil \\ Colégio Militar do Rio de Janeiro (CMRJ), Rio de Janeiro, Rio de Janeiro / Brasil \\ amaury.garcia@gmail.com \\ https://orcid.org/0000-0001-6564-2424
}

Resumo: Este artigo analisa representações da experiência de lazer de personagens jovens pertencentes às classes trabalhadoras da Escócia, nos romances Trainspotting e Cola, de Irvine Welsh, considerando o contexto histórico em que as narrativas se situam: a era Thatcher. Tal experiência, em meio a uma realidade de diminuição do estado de bemestar, escassez de oportunidades e desemprego em massa, é atravessada por dois fatores: escapismo, evidenciado pelo uso de heroína; e violência, evidenciado pelo abuso de álcool e por disputas de torcidas organizadas de clubes de futebol, o chamado hooliganismo. Busco demonstrar de que forma as políticas do governo Thatcher, de pensamento e agenda neoliberais, são representados como fator relevante para moldar a experiência de lazer da juventude de classes menos favorecidas da Escócia nos romances selecionados. Palavras-chave: Escócia; Irvine Welsh; classe trabalhadora; lazer; violência; escapismo.

\begin{abstract}
This article analyses representations of the experience of leisure by young characters who belong to the working classes of Scotland, in Irvine Welsh's Trainspotting and Glue, considering the historical context upon which the narratives are based, i.e. Thatcher's era. Such experience - based on a reality of a shrinking welfare state, lack of opportunities and mass unemployment - is informed by two factors: escapism, evidenced by heroin use; and violence, evidenced by alcohol abuse and football hooliganism. I intend to discuss how the politics of Thatcher's rule, and its neoliberal thought and agenda, are represented as a key factor in shaping the experience of leisure of the youth of underprivileged classes in Scotland in the selected novels.
\end{abstract}

Keywords: Scotland; Irvine Welsh; working class; leisure; violence; escapism. 


\section{Introdução}

O presente artigo aborda representações da experiência de lazer da juventude de classes menos favorecidas, oriundas de Edimburgo, capital da Escócia, durante a década de 1980, nos romances Trainspotting (2014 [1993]) e Cola (2019 [2001]), de Irvine Welsh, tendo como foco o uso de álcool e de heroína por parte das personagens, bem como seu envolvimento em atividades violentas. A relação de tais jovens com a ideia de lazer ocorre principalmente por duas vias: o escapismo e a violência. Em relação à primeira, destaco o abuso de heroína. No que tange à segunda, ressalto um contexto fortemente marcado pela cultura do alcoolismo, assim como o submundo das torcidas organizadas de futebol, fenômeno conhecido como hooliganismo.

A ação de ambos os romances situa-se majoritariamente em Leith, distrito da periferia de Edimburgo, conhecido por sua população marginalizada, pertencente às classes trabalhadoras. Trainspotting e Cola cobrem principalmente as décadas de 1980 e 1990, com ênfase na era Thatcher. Considerando tais fatores, busco contextualizar historicamente as obras, em relação a questões sociais e políticas pertinentes ao período em que se inserem e/ou retratam. A partir desse contexto, discuto a noção de lazer e como esta se relaciona com o abuso de substâncias e o hooliganismo, procedendo à análise dos romances, numa tentativa de debater as representações da experiência de tais fenômenos pela juventude das classes operárias de Edimburgo.

\section{Contexto histórico e Irvine Welsh}

Há dois fatos históricos que têm fundamental importância não apenas na obra de Welsh, mas na literatura escocesa produzida nas três últimas décadas do século XX. O primeiro é o fracassado referendo de devolução do parlamento escocês realizado em 1979. O segundo referese ao governo de Margaret Thatcher e seu legado.

Robert Morace (2007, p. 24) explica que o sentimento de orgulho nacional na Escócia teve crescimento considerável nas décadas de 1960 e 1970, culminando no Scotland Act de 1978, que propôs um referendo público acerca da reabertura do parlamento escocês, fechado desde o início do século XVIII. Com a coroação de James VI, monarca da Escócia, como James I, monarca da Inglaterra e Irlanda, em 1603, ocorreu a 
chamada União das Coroas, iniciando um longo processo de centralização de poder abrangendo tais nações. Do ponto de vista político, o processo culmina com o fechamento definitivo do parlamento escocês em 1707, ano a partir do qual o trabalho legislativo passou a ser realizado no Parlamento de Westminster, situado em Londres, Inglaterra. Desde então, os direcionamentos políticos que definiam os rumos dos três países eram decididos levando em consideração interesses majoritariamente ingleses. A proposta de devolução do parlamento à Escócia, contemplada no ato de 1978, possibilitaria restaurar poderes políticos gradualmente perdidos desde seu fechamento, principalmente no âmbito interno do país.

Apesar de a maioria ter votado a favor da reabertura, o referendo fracassou por não ter cumprido uma exigência que o Parlamento de Westminster adicionou como emenda ao processo: pelo menos $40 \%$ de todo o eleitorado escocês deveria votar em favor da devolução. $\mathrm{O}$ resultado foi considerado inválido, uma vez que o quórum de votantes não permitiu que esse número fosse atingido. Morace (2007, p. 24) argumenta que tal emenda passou a ser vista tanto como traição por parte dos ingleses quanto como covardia por parte dos escoceses, gerando fortes sentimentos de autodesprezo pessoal e nacional entre estes.

No mesmo ano do frustrado referendo, a líder do partido conservador, Margaret Thatcher, foi eleita Primeira-Ministra do Reino Unido. Por onze anos, Thatcher introduziu políticas neoliberais que afetaram profundamente as classes trabalhistas britânicas. Apesar de ser um termo controverso, entende-se neoliberalismo, para os propósitos deste trabalho, de acordo com a definição de David Harvey (2007, não paginado, tradução própria):

Neoliberalismo é, em primeira instância, uma teoria de práticas político-econômicas que propõe que o bem-estar humano pode ser melhor buscado pela liberação de liberdades e habilidades empreendedoras individuais dentro de uma estrutura institucional caracterizada por fortes direitos à propriedade privada, livre mercado e livre comércio. O papel do Estado é criar e preservar uma estrutura institucional apropriada a tais práticas. O Estado deve garantir, por exemplo, a qualidade e integridade do dinheiro. Deve, também, organizar funções e estruturas militares, defensivas, policiais e legais a fim de assegurar direitos à propriedade privada e garantir, por meio de força se necessário, $\mathrm{o}$ funcionamento apropriado dos mercados. Além disso, se mercados não existirem (em áreas como propriedade, água, educação, saúde, 
seguro social ou poluição ambiental) devem, então, ser criados, por ação estatal se necessário. Mas, além dessas tarefas o Estado não deve agir. ${ }^{1}$

Entende-se liberdade para empreender como atividade diretamente relacionada à acumulação de capital, visto que é possível investir em mercados apenas quando há dinheiro para tal. Em outras palavras, as estruturas políticas e econômicas requisitadas pelo pensamento neoliberal respondem aos interesses daqueles que já concentram riquezas, como grandes empresas privadas que são controladas, por sua vez, por elites financeiras. Essa é uma das razões para que Harvey (2007) argumente que o neoliberalismo, em última instância, serve a um projeto de restauração de poder para as classes altas.

Seguindo tais ideais, as políticas do governo Thatcher reduziram consideravelmente o papel do Estado na sociedade ao passo que encorajaram a iniciativa privada. Primordialmente, isso provocou uma alteração de mentalidade do povo britânico, que passou a se centrar cada vez mais em ações individuais e a buscar menos soluções de viés comunitário. Harvey (2007) explica que as decisões durante o mandato de Thatcher implicaram as seguintes ações:

confrontar sindicatos, atacar todas as formas de solidariedade que atrapalhassem a flexibilidade competitiva [...], desmantelar ou reduzir compromissos com o estado de bem-estar, privatizar empreendimentos públicos (incluindo projetos habitacionais), reduzir impostos, encorajar o empreendedorismo e criar um clima favorável no mundo dos negócios que trouxesse um forte investimento estrangeiro [... $]^{2}$. (HARVEY, 2007, tradução própria)

\footnotetext{
1 "Neoliberalism is in the first instance a theory of political economic practices that proposes that human well-being can best be advanced by liberating individual entrepreneurial freedoms and skills within an institutional framework characterized by strong private property rights, free markets and free trade. The role of the state is to create and preserve an institutional framework appropriate to such practices. The state has to guarantee, for example, the quality and integrity of money. It must also set up those military, defence, police, and legal structures and functions required to secure private property rights and to guarantee, by force if need be, the proper functioning of markets. Furthermore, if markets do not exist (in areas such as land, water, education, health care, social security, or environmental pollution) then they must be created, by state action if necessary. But beyond these tasks the state should not venture."

2 "confronting trade union power, attacking all forms of social solidarity that hindered competitive flexibility [...], dismantling or rolling back the commitments of the welfare
} 
Como o proletariado do Reino Unido dependia, em grande parte, de companhias estatais, a consequência do novo direcionamento foi extremamente negativa para os trabalhadores. Não poderia ser pior na Escócia, por ser um país não apenas governado pelo parlamento situado em Londres, mas por ser uma região cuja economia baseava-se em atividades industriais. Peter Clarke (2004, p. 372) assevera que as taxas de desemprego cresceram dramaticamente, atingindo níveis jamais vistos, principalmente em regiões industriais, como a Escócia, Gales e o norte da Inglaterra. Não é surpresa que, durante tal período, os escoceses tenham experimentado um sentimento de alienação e de opressão pelo modo de ser britânico (Britishness) cada vez mais intenso, já que as novas políticas iam de encontro ao comportamento do povo escocês, fortemente baseado em valores socialistas, trabalhistas e comunitários (MORACE, 2007, p. 24).

O governo Thatcher afetou não apenas a Escócia, mas mudou a realidade social do Reino Unido como um todo. Privatizar era a ordem do dia, uma vez que muitos serviços essenciais nacionais foram vendidos à iniciativa privada, especialmente nos campos das telecomunicações e transporte. De acordo com Clarke (2004, p. 381), a privatização tornou-se a política mais dinâmica da Era Thatcher. Simultaneamente, áreas que permaneceram públicas, como a educação básica ou o serviço nacional de saúde, passaram a seguir novas regras administrativas, típicas do mundo corporativo (VERNON, 2017, p. 488).

A Primeira-Ministra aproveitou as chances que teve durante a greve dos mineiros, que durou de março de 1984 a março de 1985, para mudar regras acerca do funcionamento de sindicatos, que, por sua vez, gradualmente perderam o poder que haviam conquistado por anos de lutas. Além disso, a maneira brutal com a qual o governo lidou com a greve impôs derrotas significativas para práticas sindicalistas: altercações entre a força policial e manifestantes grevistas resultaram não apenas em prisões, mas em um considerável número de feridos e até mesmo mortos. A brutalidade usada pela polícia contra manifestantes em Orgreave, ${ }^{3}$ por exemplo, passou a ser a tônica para abordar greves no Reino Unido (VERNON, 2017, p. 498-499).

state, the privatization of public enterprises (including social housing), reducing taxes, encouraging entrepreneurial initiative, and creating a favourable business climate to induce a strong inflow of foreign investment [...]".

3 A "Batalha de Orgreave", como ficou conhecida, ocorreu em Yorkshire, em junho de 1984. O sindicato nacional dos mineiros organizou um piquete contando com cerca de seis mil trabalhadores para impedir o funcionamento de uma fábrica. Entretanto, foram confrontados por um número maior de policiais, que usaram violência jamais vista em 
James Vernon (2017,p. 486) argumenta que o ataque aos sindicatos foi, também, de suma importância para a desregulamentação do mercado de trabalho. Isso trouxe maior liberdade e autonomia a empresas acerca do que exigir de seus empregados. Dessa forma, a classe trabalhadora foi forçada a aceitar fazer mais sem necessariamente receber melhores salários. Consequentemente, devido ao acúmulo de funções que um trabalhador passou a exercer, os índices de demissões e desemprego saltaram a níveis jamais vistos, gerando maior concentração de renda nas mãos das elites e maior escassez financeira às classes menos favorecidas.

Soma-se a isso o advento da globalização. Com a automação de parte do trabalho industrial e a transferência de produção para países em que a mão de obra é consideravelmente menos custosa, fenômeno conhecido como outsourcing, muitos ofícios tornaram-se virtualmente extintos em países desenvolvidos. No Reino Unido, por exemplo, muitas companhias transferiram seus polos industriais para países no sudeste asiático, antigos membros do Império Britânico (VERNON, 2017, p. 487-488).

$\mathrm{O}$ período Thatcher é, então, marcado por uma transição da noção de estado de bem-estar provido pelo governo para um pensamento voltado ao individualismo e ao empreendedorismo privado, favorecendo o grande capital. Essa mudança é resumida em uma de suas mais famosas citações: "a sociedade não existe. Há indivíduos, homens e mulheres, e há famílias. E nenhum governo pode fazer qualquer coisa exceto por meio das pessoas, e as pessoas devem cuidar de si próprias primeiramente"4 (THATCHER, 2013, tradução própria). A partir de então, o cidadão comum passou a experimentar certo senso de abandono, já que não mais podia esperar ser auxiliado pelo Estado.

Irvine Welsh capturou tal sentimento em seu país de origem. Ele pertence a uma geração de escritores escoceses que abordam, por perspectivas distintas, problemas relacionados a questões como língua e identidade nacionais, crítica social e tradição literária, dentre outros tópicos. Romancistas como James Kelman, Alasdair Gray e Alan Warner, para mencionar alguns, fazem parte desse grupo que problematiza o fato

manifestações até aquele momento no Reino Unido. O confronto resultou em diversos feridos e noventa e três pessoas presas (VERNON, 2017, p. 498).

4 “'(...) there's no such thing as society. There are individual men and women and there are families. And no government can do anything except through people, and people must look after themselves first." 
de a Escócia ser uma nação ainda controlada por um governo conservador situado em outro país. Como argumenta David Leishman (2006, p. 124, tradução própria):

O contexto sociopolítico permanece importante como nunca numa literatura escocesa que se mostra, pela recorrência de suas preocupações temáticas - opressão linguística, insatisfação constitucional, os efeitos desestabilizantes de uma rápida desindustrialização, a alienação que acompanha o capitalismo moderno -, ser dolorosamente consciente do contexto de sua produção. ${ }^{5}$

A partir disso, as narrativas de tais escritores tendem a girar em torno das classes trabalhadoras, já que focalizam as consequências negativas que o proletariado escocês teve de enfrentar devido a políticas britânicas, que, em geral, seguiram uma agenda neoliberal. Talvez seja essa a razão para que a ficção escocesa produzida nas últimas quatro décadas tenha se aproximado de uma estética de realismo cru, para representar o contexto de escassez e penúria em áreas urbanas (LEISHMAN, 2006, p. 124).

Welsh é um dos romancistas que se destaca por retratar os efeitos nocivos do capitalismo tardio e de políticas neoliberais sobre a classe operária de sua terra natal. Em seus romances, o escritor aborda a dura realidade de membros marginalizados da sociedade escocesa em um contexto pós-industrial, centrando-se, muitas vezes, na violência que parece ser inerente a suas vidas. Suas narrativas lidam com temas como abuso de drogas, alcoolismo, violência, crime, abandono parental, pobreza, abandono e autoritarismo do Estado, entre outros. Seu olhar é crítico e pungente, seu discurso ácido, escancarando as mazelas da sociedade capitalista ocidental contemporânea, com foco nas especificidades de seu país.

Suas personagens são cidadãos comuns: trata-se de operários ou trabalhadores da área de serviços, muitos deles desempregados. Uma parcela vive de seguro-desemprego ou de pequenos trabalhos informais, outra parte depende, em muitos casos, de atividades ilegais, como roubos, tráfico de drogas, proxenetismo ou "esquemas". Este vocábulo remete a

5 "The socio-political context remains ever important in a Scottish literature which shows itself, by its recurring thematic concerns - linguistic oppression, constitutional dissatisfaction, the destabilising effects of rapid deindustrialisation, the alienation that accompanies modern capitalism - to be painfully aware of the context of its production". 
um dos fatores mais intrigantes do universo de seus romances: o fato de a maioria de suas personagens ser formada por schemies, termo utilizado para se referir a pessoas originárias dos housing schemes, projetos habitacionais construídos para abrigar a população de baixa renda. Entretanto, além desse significado, o termo pode ser traduzido como "esquema", trazendo a ideia de um plano engendrado para conseguir algum tipo de vantagem. Destarte, os schemies poderiam ser vistos simultaneamente como moradores de projetos habitacionais e como pessoas sempre dispostas a tirar algum proveito de situações em que estejam inseridos.

Os schemies de Welsh têm mais um ponto em comum: são, em sua maioria, Leithers, isto é, originários do bairro de Leith. Dos doze romances publicados pelo escritor até o momento, dez deles apresentam personagens que vêm desse distrito. Seus universos se sobrepõem, já que personagens centrais de um romance aparecem de forma periférica em outros. Uma leitura ampla de seus escritos sugere que ele descreve a vida em Leith, como se estivesse apresentando uma coletânea de crônicas do local.

O autor de Trainspotting e Cola nasceu em Edimburgo em 1961 (MORACE, 2001, p. 8). Cresceu em um conjunto habitacional similar aos de Leith, no distrito de Muirhouse, região que seria invadida pela heroína nos anos oitenta e ficou conhecida como uma área de alta incidência de AIDS, devido ao compartilhamento de agulhas para uso do entorpecente. Quando jovem, Welsh trabalhou no setor de serviços em sua cidade natal, se mudando para Londres, no fim dos anos setenta, para se juntar à cena punk. Depois de passar alguns anos como músico frustrado na capital inglesa e de se envolver no submundo do crime e das drogas, o que o levou a ser repetidamente preso, Welsh começou a trabalhar no mercado imobiliário de Londres, que estava em franca expansão no início dos anos oitenta. Tendo adquirido algum capital, retornou a Edimburgo e passou a trabalhar como servidor no conselho habitacional da cidade, o que o pôs novamente em contato com os housing schemes.

No início dos anos noventa, motivado pela cena de música rave e por ter cruzado caminhos com escritores e editores, como Duncan McLean, Kevin Williamson e Alan Warner, Welsh decidiu aproveitar o material de antigos diários e começou a escrever ficção. Logo conseguiu publicar alguns contos em revistas locais novas, cujos editores buscavam apresentar uma literatura que falasse sobre a Escócia real e cotidiana, das classes menos favorecidas, em oposição à literatura do establishment londrino (KENNEDY, 2019). Em 1993, seu primeiro 
romance, Trainspotting, é publicado. O livro foi um sucesso, alcançando níveis de venda fora do previsto. Depois de ser adaptado para o cinema em 1996, Welsh tornou-se uma celebridade literária, com uma legião de fãs. Consequentemente, os ganhos financeiros lhe permitiram dedicação exclusiva ao trabalho de escritor.

Como mencionado, suas obras lidam constantemente com os Leithers. O escritor aborda seu modo de ser e estar no mundo, seu comportamento social. Welsh apresenta a cultura local em todos os seus aspectos, sem esconder seu lado sombrio. Apesar de suas personagens serem marginalizadas e exploradas pelos ricos e poderosos, elas não são representadas como sendo superiores moralmente, fator que diferencia Welsh de outros escritores de sua geração (MORACE, 2001, p. 26-7). Seus Leithers são misóginos, racistas, machistas, homofóbicos, rudes, cruéis, violentos, tanto quanto o governo que os abandonou e as elites que os exploram.

Tal aspecto é representado não apenas pelos atos das personagens, mas também pela própria linguagem em que se expressam. Welsh busca reproduzir graficamente os ritmos, cadências e pronúncia da linguagem das ruas de sua cidade, soletrando as palavras diferentemente da norma padrão da língua inglesa. Não se trata do Scots literário, usado por escritores escoceses canônicos, como Sir Walter Scott ou Robert Burns, mas de um formato mais moderno e brutal, chamado de "Scots metropolitano" (SKINNER, 1999, p. 218). Tal variação é recheada de gírias e vocábulos de baixo calão, representando vários dos preconceitos característicos da população local. Morace (2001, p. 26) ressalta que o efeito provocado é mostrar a realidade nua e crua das ruas de Edimburgo, sem romantizar a classe operária.

Tal brutalidade, representada por Welsh como aspecto que advém do contexto de escassez e abandono enfrentado pela classe trabalhadora escocesa durante o governo Thatcher, constitui uma das características mais marcantes de sua obra, estando presente em várias esferas de atividades sociais de suas personagens, como o trabalho, a família, a escola e o tema deste artigo, o lazer.

\section{Lazer em Irvine Welsh: álcool, hooliganismo e heroína}

Em The Serious Leisure Perspective, Robert Stebbins e Sam Elkington (2014, p. 5) definem lazer como "atividade voluntária e 
contextualmente configurada com a qual o indivíduo se engaja durante seu tempo livre, que a pessoa deseja realizar e, usando suas habilidades e recursos, de fato a realiza de forma prazerosa ou gratificante. ${ }^{\prime 6}$ Os autores prosseguem, destrinchando a definição, ao explicar que o lazer pode ser concebido de maneiras variadas, por ser historicamente e socialmente condicionado, já que certas atividades são compreendidas como adequadas em um período histórico ou em uma determinada sociedade, mas não em outra. Stebbins e Elkington (2014, p. 6) mencionam, também, a questão econômica, ao mostrarem que muitas das atividades de lazer de um grupo social não consistem em opções para outros grupos, devido aos custos em que o indivíduo deve incorrer para realizá-las.

Stephen Page e Joanne Connell (2010, p. 10-12) seguem uma linha semelhante em Leisure: an Introduction, ao definirem lazer, em linhas gerais, seguindo três pressupostos básicos: trata-se de atividades realizadas pelo indivíduo em seu (1) tempo livre, (2) que sejam prazerosas e que necessariamente sejam entendidas como (3) contrárias ao conceito de trabalho, sendo este compreendido como atividade laboral que gera renda para subsistência ou atividades rotineiras obrigatórias. Os autores também consideram aspectos como contexto histórico e social para que uma atividade seja considerada lazer, além de complexificar ainda mais as possibilidades de abordagem do tema. ${ }^{7}$

Em complemento às noções acima demonstradas, faço referência a Quest for Excitement: Sport and Leisure in the Civilizing Process, de Norbert Elias (1986). O autor (1986, p. 41-42) afirma que a vida em sociedade impõe uma série de limites às nossas pulsões, gerando constante tensão. O lazer existiria, em sua concepção, para que sublimemos tal tensão de forma segura, sem gerar riscos ao indivíduo ou à comunidade.

Entretanto, as formas de entretenimento e lazer apresentadas por Welsh em sua obra contradizem a concepção de Elias, no sentido de causarem problemas à comunidade. Trata-se do que autores como

\footnotetext{
6 "un-coerced, contextually framed activity engaged in during free time, which people want to do and, using their abilities and resources, actually do in either a satisfying or a fulfilling way".

7 Não é propósito deste artigo discutir possíveis abordagens ao conceito de lazer e as imbricações e complexificações que tais abordagens podem trazer. Para fazê-lo, seria necessário um texto de maior fôlego. $\mathrm{O}$ presente artigo enfoca a experiência de lazer pelas classes trabalhadoras de Edimburgo como representada na obra de Irvine Welsh.
} 
Stebbins e Elkington (2014, p. 184) chamam de lazer desviante. Grosso modo, são atividades que envolvem comportamentos antissociais, muitas vezes violentos, e danosos, tanto para o indivíduo quanto para a sociedade. Os autores $(2014$, p. 184) citam práticas como uso de entorpecentes, abuso de álcool, atos de delinquência e pequenos crimes, sexo em grupo, dentre outros.

Em diversas entrevistas, Welsh ressalta uma realidade específica experimentada pela juventude das classes operárias escocesas que viveram a década de oitenta: eles tinham muito tempo livre, devido às altas taxas de desemprego. Considerando a violência sistêmica promovida por forças policiais a que tais classes eram expostas, os valores cada vez mais individualistas que ganhavam primazia, a ideia de competitividade do mundo corporativo que adentrava o comportamento social e a construção de uma sociedade de consumo que visava transformar praticamente toda experiência humana em produto vendável, incluindo o prazer, chega-se a um contexto em que o conceito de lazer se torna ambíguo, ou, até mesmo, perverso. Podem-se depreender duas motivações básicas nas atividades de lazer das personagens dos textos selecionados: (1) uma tentativa de, por meio do uso de heroína, anestesiar a existência, quase intolerável, que a juventude escocesa menos favorecida economicamente enfrentava; e (2) uma busca por autoafirmação identitária que se opõe às elites e a grupos diferentes de forma violenta, expressa pelo hooliganismo e intensificada pela cultura do alto consumo de álcool.

Anthony Cooke, em A History of Drinking: The Scottish Pub since 1700 (2015), explica que a socialização por meio do consumo de álcool em bares faz parte do tecido social escocês há séculos. $\mathrm{O}$ pub (abreviação de Public House) tem uma centralidade na vida escocesa, dado o fato de ser um dos locais em que diversos rituais sociais têm sido celebrados, como casamentos, funerais, dentre outros (COOKE, 2015, p. 2). Além disso, tais bares são, há décadas, um dos principais locais de encontro para amigos e colegas de trabalho para relaxar depois do expediente, buscando, justamente, distração de seus afazeres. A importância do pub para o proletariado escocês é notória, pois abrigava, no século XIX, reuniões de sindicatos para que seus membros pudessem conduzir discussões políticas acerca de seus ofícios, como também organizar greves, oferecendo um espaço mais democrático do que as fábricas (COOKE, 2015, p. 4). Além dos pubs, que têm horários determinados para seu funcionamento, os escoceses contam com as off-licences, lojas 
que vendem bebidas alcoólicas a qualquer horário do dia. Apesar de seu potencial como substância recreativa, sabe-se que o álcool pode gerar efeitos seriamente nocivos, não apenas no âmbito individual como também no social. Nesse sentido, para a discussão promovida neste artigo, cabe destacar seu caráter potencializador de condutas violentas.

Ao debater o problema de violência em sua terra natal, em artigo publicado pelo periódico britânico The Guardian, intitulado "Scotland's Murderous Heart", Welsh (2005) argumenta que os hábitos etílicos das classes menos favorecidas escocesas são diferentes dos costumes de outras nacionalidades. Em primeiro lugar, há bebidas de custo reduzido com teores alcoólicos elevados em oferta na Escócia, o que facilita seu consumo por indivíduos com pouco dinheiro. Soma-se a isso o fato de que os projetos habitacionais são situados nas periferias dos centros urbanos, onde não há uma preocupação e tampouco um monitoramento eficaz em relação à segurança pública por parte das autoridades. Diante de uma sociedade cada vez menos centrada em valores comunitários e mais preocupada com o indivíduo, Welsh (2005) afirma que os destituídos buscam emoções fortes no intuito de trazer sentido às suas vidas. Considerados tais fatores, o escritor conclui que a mistura álcool e drogas incita comportamentos antissociais, que levam, na maioria dos casos, a atos de agressão física extrema. Em uma passagem do texto, Welsh (2005) relata a experiência de ir à cremação de mais um jovem que conhecia, vítima de assassinato em uma briga de bar, e reflete sobre a relação entre álcool e violência na sociedade escocesa contemporânea:

Senti-me profundamente chocado ao me dar conta de quantas vezes eu havia passado por versões dessa cena anteriormente; ao testemunhar as vidas de uma família arruinadas porque um de seus membros foi a vítima ou o perpetrador desse tipo de violência tão entrelaçada ao tecido social escocês a ponto de se tornar banal. ${ }^{8}$ (WELSH, 2005, tradução própria)

Abundam exemplos de violência causada por personagens inebriadas em seus romances. Há um capítulo em Trainspotting, em especial, no qual o escritor busca contrastar a atmosfera do elegante centro

\footnotetext{
8 "It forcibly struck me then just how many times I had been through different versions of this scene before; witnessing a family's lives wrecked because one of its members was a victim or perpetrator of the kind of violence so interwoven into the fabric of Scottish social life as to be almost mundane".
} 
de Edimburgo, voltado ao turismo, ao contexto da cruel realidade de desamparo dos subúrbios. Mark Renton, uma das principais personagens do romance, acaba de voltar de Londres para passar as festas de fim de ano em sua cidade natal. Ele descreve sua saída da Estação Ferroviária de Waverley, situada no centro da cidade, e sua caminhada até Leith, percorrendo o trajeto conhecido como Leith Walk. Em certo momento, ele nos fala sobre um grupo de bêbados que saíra de um bar:

Três caras saem tropeçando de um $p u b$ e entram num restaurante chinês. Um dos caras tá fazendo de tudo pra que a gente se encare. Tem uns otários metidos a durões que se agarram com as duas mãos em qualquer pretexto pra quebrar a cara de alguém, por mais babaca que seja. Sigo na velha tática de caminhar ainda mais rápido.

Pensando nas probabilidades, quanto mais eu avançar na Walk a essa hora da noite, maior minha chance de acabar sem dentes. (WELSH, 2014, p. 297)

Apesar de Renton conseguir evitar uma briga, a aura de ameaça chega a ser tangível na passagem. Ao demonstrar que os indivíduos que saíram do $p u b$ estavam não apenas embriagados, mas dispostos a arrumar confusão com qualquer pessoa com quem travassem contato, a descrição explicita o abuso de álcool e sua ligação com condutas violentas como traço marcante da experiência dos Leithers.

Uma das figuras mais exemplares do romance no que tange à correlação entre alcoolismo e violência é Francis Begbie, também conhecido pela alcunha de Generalísimo Franco, que o compara ao temido ditador espanhol. Trata-se de um marginal local, um jovem bruto e violento, que inspira medo em todos à sua volta, mesmo naqueles que fazem parte de seu círculo de amizades. Além de ser alcoólatra e usuário de cocaína, Begbie é viciado em violência. Seu comportamento rude e agressivo representa uma espécie de recontextualização exagerada e difusa da ética do operariado.

Uma das passagens que se destaca acerca dele e de seus problemas com alcoolismo ocorre em um capítulo em que Renton o encontra em um pub. Ao chegar no bar, Renton nota que Begbie, que o esperava, já estava levemente embriagado. Depois de um tempo, um grupo de jovens adentra o local, causando certo alvoroço. A narrativa em primeira pessoa, na voz 
de Renton, ${ }^{9}$ transmite temor pelos prospectos que a noite traz, quando a personagem vai ao balcão para comprar mais algumas bebidas: "Meu rosto fica vermelho e formigando, à espera de um soco ou uma garrafada" (WELSH, 2014, p. 80). A passagem aponta para a alta incidência de ações violentas em torno da cultura do álcool, demonstrando que brigas são tão comuns a ponto de serem previstas como parte integrante da experiência em ocasiões que deveriam servir como simples momentos de lazer aos sujeitos envolvidos.

Durante o episódio, no que parece ser uma provocação arbitrária, Begbie joga uma caneca vazia em direção ao grupo que acabara de chegar, atingindo um indivíduo e ferindo sua cabeça. A confusão, então, se inicia, com uma briga que toma grandes proporções, até o ponto em que Begbie, que já está fora do bar, é descrito chutando uma vítima que se contorce no chão. Quando Renton consegue pará-lo, ele afirma estar se vingando de uma disputa antiga. Renton nos confidencia que aquilo não passava de "munição moral fraudulenta que [Begbie] precisava pra justificar mais uma de suas batalhas movidas a álcool e fúria contra a população local" (WELSH, 2014, p. 82). A citação aponta, mais uma vez, para a banalidade da violência, visto que as justificativas para o conflito são interpretadas por Renton como mentiras. $\mathrm{O}$ fato de as ações de Begbie serem influenciadas pelo consumo excessivo de álcool reforça a representação da substância como potencial provocador de comportamentos antissociais.

A ligação entre o excesso de consumo de bebidas alcoólicas e violência reaparece em Cola, manifestada por uma das personagens principais ${ }^{10}$ Billy Birrell. Ele perde completamente o controle durante um episódio de embriaguez na viagem que faz à Alemanha. Birrell, juntamente com os outros três amigos que formam o eixo central do romance, visitam Munique durante a Oktoberfest. Enquanto estão no festival, Birrell ataca gratuitamente algumas pessoas. Para evitar maiores

\footnotetext{
9 É importante salientar que apesar de os dois capítulos mencionados até o momento serem narrados por Renton, essa nem sempre é a regra no romance. Sua estrutura é polifônica, visto que os capítulos são narrados por diferentes personagens, com suas perspectivas sobre a realidade. A mesma técnica é usada em Cola, o outro romance que faz parte do corpus deste artigo.

${ }^{10}$ Tanto em Trainspotting quanto em Cola não há um protagonista no sentido tradicional. Ambos os romances narram as histórias de um grupo de amigos, que são todos personagens principais.
} 
confusões, o grupo de amigos decide se retirar do evento. Terry Lawson, um dos companheiros, comenta que havia visto Birrell "distribuindo uns socos (...). Realmente perdeu o fio da meada, porque nem estava sendo incomodado pelos caras. Não sabe mais biritar" (WELSH, 2019, p. 305). O episódio é revelador, pois a personagem é construída como um dos indivíduos mais sérios e centrados do romance, justamente por focar suas energias no esporte, já que é um talentoso boxeador profissional em ascensão. Apesar de frio e contido durante boa parte da narrativa, o álcool faz com que Birrell simplesmente perca a noção da realidade e aja de forma inapropriada.

Além de sua ligação com a cultura dos pubs, o contexto de violência é explorado por Welsh por meio de outra atividade típica dos jovens pertencentes a classes menos favorecidas da Escócia na década de oitenta: o hooliganismo. Convidado a escrever a apresentação para as memórias de Andy Blance, um dos hooligans mais notórios da Escócia, Welsh comenta que a violência no futebol se tornou um estilo de vida nos anos oitenta (WELSH, 2010). Nesse texto, o romancista relembra que os índices de desemprego no Reino Unido saltaram de 1,2 milhões em 1979 para 3,6 milhões em 1983, levando vários jovens desesperados a sucumbir à heroína na Escócia. Diante disso, o escritor afirma que uma torcida organizada poderia servir como alternativa, por ser capaz de nutrir um senso de orgulho, pertencimento e comunidade entre seus membros.

Tal senso de pertencimento trazido por torcidas organizadas é abordado por um grupo de sociólogos em Sport and Violence in Europe (BODIN et al., 2005). Os autores defendem que a violência no esporte, por parte dos fãs, existe desde a antiguidade, mas reconhecem que há elementos inéditos no hooliganismo. Suas observações, corroborando a visão de Welsh, indicam que um contexto em que as vidas de jovens trabalhadores são consideradas dispensáveis pode levar a juventude a buscar autoafirmação por meio da violência:

Hooliganismo foi, para eles, uma forma de ser, uma maneira de se apresentar e se destacar da multidão, um modo de cultivar o que os fazia diferentes. A cultura e violência dos fãs oferecia uma alternativa à miserável e sórdida existência diária. Eles representavam uma fuga de uma rotina tediosa e ofertavam uma base e um senso de propósito para pessoas que não tinham visão de futuro. A violência extrema praticada por tais grupos lhes trazia reconhecimento social e os habilitava [...] a forjar uma identidade 
que talvez seja excessivamente feia, mas preferível ao desprezo ou infâmia social. ${ }^{11}$ (BODIN et al., 2005, p. 32, tradução própria)

O romance em que Welsh melhor explora o assunto é Cola. Ao longo da narrativa, ocorre um encontro entre o Hibernian Football Club, time de Edimburgo, muito popular em Leith, e um dos clubes mais bemsucedidos da história do futebol na Escócia, o Glasgow Rangers. Seguindo um plano previamente organizado, típico da violência futebolística da década de oitenta, o grupo de quatro amigos protagonistas, em conjunto com outros jovens marginais de Leith, adentra o estádio passando-se por torcedores dos Rangers. Durante o primeiro tempo, eles iniciam agressões contra os torcedores rivais nos banheiros do estádio. Depois de atacarem algumas vítimas, voltam às arquibancadas e a confusão generalizada começa. O caos é instaurado, até que a polícia chega para apartar a briga. Os torcedores do Hibernian são retirados da arquibancada reservada aos Rangers, sendo alguns deles detidos. Terry Lawson, então, ergue o cachecol com as cores do Hibernian, ato que causa grande clamor de aprovação por parte da torcida de seu clube. Aí jaz o reconhecimento social que Bodin menciona: não se trata simplesmente de violência, mas de se destacar, de aparecer como alguém acima do contexto de escassez que os cerca.

Isso pode ser observado pela narrativa de Andrew Galloway, uma das personagens do grupo principal, quando ele nos conta que, ao adentrar um $p u b$, é tratado como herói por ter participado da confusão no estádio:

Lá dentro já tem um monte de gente, Dozo e sua turma, e nós começamos a contar as histórias outra vez. Então Terry e Marty Gentleman chegam, recebidos com grandes vivas por Dozo e parte da rapaziada. Todos perguntam o que aconteceu na polícia, vez após vez. Tratados como heróis, porra. Maneiro. (WELSH, 2019, p. 116)

\footnotetext{
11 "Hooliganism was for them a way of being, a manner of presenting themselves and standing out from the crowd, a way of cultivating what made them different. Fan culture and violence offered an alternative to a miserable and sordid day-to-day existence. They represented an escape from a deadly-dull routine and provided a base and a sense of purpose for people who lacked any vision of a future. The extreme violence practised by such groups earned them social recognition and enabled them [...] to forge an identity which might have been exceedingly ugly but was preferable to contempt and social denigration."
} 
Terry destaca-se ainda mais que os outros. Sendo o único maior de idade dentre os que foram detidos, ele é, também, o único a ter seu nome mencionado nos jornais locais. Tal menção gera orgulho à personagem, que demonstra se conceber como superior. A representação que Welsh faz do fã violento de futebol ressalta o sentimento de pertencimento e destaque a que Bodin se refere na citação transcrita anteriormente. Mesmo que por meios negativos, o hooliganismo gera um senso de comunidade e poder para indivíduos que vivem um contexto de privação e abandono. A violência torna-se, então, uma das principais alternativas ligadas ao lazer para os jovens representados. Somando o consumo desenfreado de álcool ao hooliganismo, cria-se uma mistura fortemente antissocial e destrutiva.

A alternativa à violência para lidar com esse contexto opressor não é positiva, muito menos construtiva. Trata-se da tentativa de se apartar por completo da sociedade por meio do abuso de heroína e seu consequente escapismo do real. Trainspotting traz a heroína como seu principal leitmotiv. O próprio título do romance faz alusão ao uso do narcótico. Em primeira instância, o vocábulo trainspotting refere-se ao hábito britânico de ir a estações ferroviárias para observar e anotar os números de trens que transitam pela estação, bem como de seus pontos de partida e seus destinos. Todavia, Tim Bell (2018) explica que o vocábulo sublinha o ato de injetar heroína: a prática deixa marcas nas veias usadas, como se fossem linhas férreas; para reconhecer facilmente outros usuários, viciados em heroína procuram por tais marcas em braços alheios, como se observassem trilhos de trens em estações ferroviárias.

Em um contexto fortemente alienante, em que o indivíduo depende somente de si próprio, não podendo se apoiar em solidariedade comunitária, o narcótico desejado é um que induza ao isolamento total, um anestésico que possa distanciar totalmente o eu da realidade, como é o caso da heroína. Como afirma Stephen Ross (2018, tradução própria),

\begin{abstract}
"em uma versão perversa do interesse individual da era Thatcher, Renton abraça a capacidade da heroína de remover o indivíduo de comprometimentos sociais, situando necessidades egocêntricas acima de qualquer forma de empatia ou obrigação comunal."12
\end{abstract}

\footnotetext{
12 "In a perverse version of Thatcheresque self-interest, Renton embraces heroin's capacity to remove the individual from social commitment, placing selfish need above any form of empathy or communal obligation".
} 
Morace (2007, p. 60, tradução própria) lista as razões que os usuários de heroína do romance oferecem para que continuem sua relação com a droga:

Contrariar o tédio, induzir o esquecimento, escapar das escolhas intermináveis do capitalismo, participar da cultura do consumo tanto como consumidor quanto como empreendedor; como 'defesa psíquica', como resposta razoável da parte do Exército de Desempregados de Thatcher, como um modo puramente arbitrário, porém efetivo, de organizar a vida, como a epítome da 'álgebra de necessidade' do capitalismo de consumo e das 'políticas de individualismo competitivo do governo Thatcher', e como a consequência lógica do liberalismo clássico que, de forma ilógica e hipócrita, proíbe certas drogas (heroína, por exemplo), mas não outras (de álcool a cartões de crédito). ${ }^{13}$

$\mathrm{O}$ contexto individualista em conjunto com uma realidade de escassez de oportunidades e meios de subsistência definiu a heroína como o narcótico da Escócia na década de oitenta. Em um capítulo intitulado "Em busca do homem interior", Mark Renton, a personagem mais consciente e articulada do romance, pondera sobre suas razões para o uso de heroína. O capítulo apresenta diálogos entre a personagem e psicólogos, assim como suas reações às conclusões de tais agentes de saúde, durante sua participação em um programa de reabilitação. Para eles, Renton se droga para efetuar ataques a autoridades que não reconhece como tal, ou porque a sociedade em que vive ignora seu valor quando ele age da forma esperada, ou que ele tem baixa autoestima e culpa o mundo por ser incapaz de lidar com as demandas da vida adulta, dentre outras razões que, para ele, soam absolutamente estúpidas. Afirma, então, que se droga por motivos absolutamente egocêntricos, por se conceber como superior à sociedade, o que o leva a tentar se desvencilhar dela.

\footnotetext{
13 "To counter the boredom, to induce oblivion, to escape capitalism's endless choices, to participate in the consumer culture as both consumer and entrepreneur; as 'psychic defence', as reasonable response on the part of Thatcher's Army of the Unemployed, as a purely arbitrary but nonetheless effective way of organizing one's life, as the epitome of consumer capitalism's 'algebra of need' and of the 'Thatcher government's politics of competitive individualism', and as the logical consequence of classical liberalism which illogically and hypocritically proscribes certain drugs (heroin, for example) but not others (from alcohol to credit cards)."
} 
Na passagem mais comumente citada do romance, Renton esclarece em que consiste, para ele, o mundo que o cerca, porque não quer fazer parte dele e como a heroína lhe oferece uma saída:

A sociedade inventa uma intrincada lógica falsa pra absorver e mudar as pessoas que têm um comportamento fora do normal. Suponhamos que eu conheça todos os prós e contras, que saiba que terei uma vida curta, que tenha uma cabeça no lugar etc. etc., mas que ainda assim queira usar heroína. Eles não vão deixar. Não vão deixar porque isso é visto como um sinal de seu próprio fracasso. $\mathrm{O}$ fato de você simplesmente escolher rejeitar o que eles oferecem. Nos escolha. Escolha a vida. Escolha pagamentos de hipoteca. Escolha máquinas de lavar. Escolha carros. Escolha ficar sentado num sofá assistindo a programas de auditório que atrofiam a mente e esmagam o espírito, enfiando uma merda de junk food goela abaixo. Escolha apodrecer mijando e se cagando em casa, um constrangimento total pros pirralhos egoístas e fudidos que você gerou. Escolha a vida.

Bem, eu escolho não escolher a vida. Se os viados não conseguem lidar com isso, a porra do problema é deles. (WELSH, 2014, p. 181)

A lista de escolhas oferecida por Renton na passagem acima põe em xeque a subjetividade da juventude escocesa que cresceu na era Thatcher. Para ser um "sujeito" na Escócia neoliberal da PrimeiraMinistra, há de se consumir os produtos e serviços enumerados. Um jovem pertencente à classe trabalhadora, que se encontra desempregado, sem oportunidades decentes de emprego, sem perspectivas reais de mudança de contexto, não tem a possibilidade de consumir. Torna-se, portanto, assujeitado. Em uma lógica perversa, a heroína leva tais indivíduos à realização extrema desse assujeitamento ao lhes remover qualquer possibilidade de expressar ou exercer uma subjetividade.

Stephen Ross (2018) assevera que a identidade de tal juventude é ancorada em um "cinismo que articula o verdadeiro legado dos anos Thatcher"14 (ROSS, 2018, tradução própria). Ross argumenta que eles são os descendentes ilegítimos da política antissocial e individualista levada a cabo pela Dama de Ferro, os filhos bastardos de um contexto em que a sociedade não funciona como base para o indivíduo. Diante de tal realidade,

14 “(...) cynicism that articulates the true legacy of the Thatcher years (...)”. 
as personagens retratadas na obra de Welsh tomam um dos dois caminhos apresentados no artigo: a violência ou o escapismo.

\section{Considerações Finais}

Como demonstrado, a realidade da classe trabalhadora escocesa retratada nas obras selecionadas foi extremamente difícil nos anos oitenta, em especial para o jovem pertencente a tal classe. Desregulamentação do mercado de trabalho, exigências de maior produtividade sem acréscimo salarial, privatização de serviços estatais, aumento exponencial das taxas de desemprego, redução do poder de atuação dos sindicatos, utilização de violência policial contra manifestantes grevistas, regras mais duras para concessão de benefícios sociais, manipulação na coleta de dados relativos ao desemprego, criação de impostos que oneraram os mais pobres e aliviaram os mais ricos, a lista é extensa. O sentimento de que o cidadão podia contar com o Estado, construído no pós-guerra, foi, assim, se dissipando. Cada um deveria cuidar de si próprio, dependendo, no máximo, de seus companheiros mais próximos. Considerando todo esse contexto, Welsh representou a juventude da classe trabalhadora escocesa da década de oitenta como indivíduos levados pelo contexto em que viviam a uma noção de lazer atravessada pela violência ou pela necessidade de escapismo. A violência concretiza-se em uma cultura dominada pelo consumo e abuso de álcool e por meio do hooliganismo, que proporciona um senso de pertencimento e de superioridade. Por outro lado, a heroína é o narcótico anestesiante capaz de trazer o esquecimento que algumas das personagens buscam para suportar a realidade. $\mathrm{O}$ resultado é um mundo cru, brutal e desesperador.

Este artigo faz parte de uma pesquisa de pós-doutoramento, ${ }^{15} \mathrm{em}$ que abordo representações de opressão e violência, concreta ou simbólica, contra a classe trabalhadora em romances de Irvine Welsh. No âmbito do presente texto, abordei a noção de opressão e violência relacionada ao lazer. Devo ressaltar que os exemplos utilizados para discussão do tema em tela não são os únicos que constam nos romances em questão. Há diversas outras passagens que poderiam ilustrar ainda mais o debate levantado. Além disso, Trainspotting é o primeiro de um quinteto de

\footnotetext{
${ }^{15}$ A pesquisa é supervisionada pela Professora Dra. Ana Lúcia de Souza Henriques, do Instituto de Letras da Universidade do Estado do Rio de Janeiro (UERJ).
} 
romances. Tal grupo apresenta passagens e episódios que contribuem para essa discussão. Contudo, o espaço de um artigo não é suficiente para cobrir o assunto em sua totalidade. Pretendo, consequentemente, debruçar-me ainda mais sobre a obra de Welsh de forma a progredir com a linha de argumentação apresentada mais detalhadamente.

\section{Referências}

BELL, Tim. Choose life. Choose Leith. Edinburgh: Luath, 2018. E-book.

BODIN, Dominique et al. Sport and Violence in Europe. Strasbourg: Council of Europe Publishing, 2005.

CLARKE, Peter. Hope and Glory: Britain 1900-2000. London: Penguin Books, 2004.

COOKE, Anthony. A History of Drinking: The Scottish Pub since 1700. Edinburgh: Edinburgh University Press, 2015.

ELIAS, Norbert; DUNNING, Eric. Quest for Excitement: Sport and Leisure in the Civilizing Process. Oxford: Basil Blackwell, 1986.

HARVEY, David. A Brief History of Neoliberalism. New York: Oxford University Press, 2007. E-book.

KENNEDY, Tristan. How Irvine Welsh Went from Enfant Terrible to the Scottish Tourist Board's Favourite Guy. In: Vice News. 18 dez. 2019. Disponível em: https://www.vice.com/en_uk/article/g5xpp7/irvinewelsh-profile-scotland-trainspotting. Acesso em: 30 abr. 2020.

LEISHMAN, David. A Parliament of Novels: the Politics of Scottish Fiction 1979-1999. In: Revue Française de Civilisation Britannique, v.14, n.1, p. 123-36, 2006.

MORACE, Robert. Irvine Welsh (New British Fiction). New York: Palgrave MacMillan, 2007.

MORACE, Robert. Welsh's Trainspotting. New York: Continuum, 2001.

PAGE, J. Stephen; CONNELL, Joanne. Leisure: an Introduction. Philadelphia: Trans-Atlantic Publications, 2010.

ROSS, Stephen. Youth Culture and the Post-War British Novel: From Teddy Boys to Trainspotting. London: Bloomsbury, 2018. E-book. 
SKINNER, John. Contemporary Scottish Novelists and the Stepmother Tongue. In: HOENSELAARS, Ton et al. (Org.). English Literature and Other Languages. Amsterdam: Rodopi, 1999. p. 211-220.

STEBBINS, Robert A.; ELKINGTON, Sam. The Serious Leisure Perspective. Abingdon: Routledge, 2014.

THATCHER, Margaret. Margaret Thatcher: a life in quotes. In: The Guardian, London, 8 Abr. 2013. Disponível em: theguardian.com/ politics/2013/apr/08/margaret-thatcher-quotes. Acesso em: 21 maio 2020.

VERNON, James. Modern Britain: 1750 to the Present. Cambridge: Cambridge University Press, 2017.

WELSH, Irvine. Cola. Tradução de Paulo Reis. 1.ed. Rio de Janeiro: Rocco, 2019.

WELSH, Irvine. Foreword. In: BLANCE, Andy. Hibs Boy: The Life and Violent Times of Scotland's Most Notorious Football Hooligan. Glasgow: Fort Publishing Ltd., 2010. E-book.

WELSH, Irvine. Scotland's Murderous Heart. In: The Guardian, London, 20 Out. 2005. Disponível em: https://www.theguardian.com/ society/2005/oct/20/penal.crime. Acesso em: 12 Out. 2018.

WELSH, Irvine. Trainspotting. Tradução de Galera \& Pellizzari. 1. ed. Rio de Janeiro: Rocco Digital, 2014. E-book.

Recebido em: 19 de dezembro de 2020. Aprovado em: 28 de abril de 2021. 